Res Pública Revista de Historia de las Ideas Políticas

ISSN: 1131-558X

https://dx.doi.org/10.5209/rpub.75412

\title{
J. Bassas, Jacques Rancière: Ensayar la igualdad, Madrid, Gedisa, 2019, 142 pp.
}

Javier Bassas escribe Jacques Rancière: Ensayar la igualdad con dos propósitos paralelos: el primero, transitar por la obra de Jacques Rancière señalando las tesis sobre la igualdad; el segundo, aportar un texto que ejercite análogamente lo descrito por el filósofo francés. El libro está motivado por el modo ranciereano de escritura; es decir, un modo ensayístico que, primero, identifica una tesis consensual y las opiniones establecidas alrededor de ésta para, posteriormente, buscar el disenso. La escritura posfundacional de Rancière, asumida por Bassas, desvela una praxis debido a que en el ejercicio de la escritura se hacen patentes los lugares de quien porta el conocimiento, de quien explica y de quien ha sido interpelado para expresarse. La emergencia de la escritura posfundacional, según el autor del libro, implica ensayar los modos en que se difuminan las jerarquías, la propiedad de la palabra -como pertenencia-y la identidad de la voz.

En la introducción, Bassas -autor y traductor del libro originalmente escrito en catalán-, se despoja de la autoridad que le ha sido conferida y que lo identifica como experto portador de palabra y de saberes. Su modo de escribir no intenta hacer descender las ideas del dominio filosófico hacia los que no saben; por el contrario, Bassas propone una distensión consigo mismo en evaluación de tres paradojas que se desprenden de la presentación de este libro a las lectoras y los lectores. La primera, corresponde al acto de escribir un libro que se opone al consenso general de que el autor es un especialista o un experto en la materia. La segunda paradoja, se deriva del consenso que adjudica a los libros un carácter explicativo. "Ahora bien, paradójicamente, este libro no querría explicar nada" (p. 19). Bassas intenta eliminar esa diferencia a partir de una escritura ranciereana, es decir, disyuntivo-conjuntiva (p. 25). Apelando a Le mâेtre ignorant (1987), Bassas prescinde la jerarquía entre el que sabe y el que no. La eliminación de esta distinción desigual muestra el compromiso del autor con el pensamiento político al que dedicará las páginas siguientes. La tercera paradoja, consiste en interrumpir el consenso sobre qué se dice y, por el contrario, acentuar el cómo. En otras palabras, Bassas invoca el disenso textual para apartarse de la preponderancia del sentido y focalizarse en las formas en que el texto produce el sentido.

En el capítulo De Althusser a los Proletarios, Bassas atiende la clara influencia de Althusser en la obra de Rancière. En concreto, analiza las referencias que aparecen en la obra temprana y que anticipan la metodología del disenso. El momento de la distancia sobrevenida entre los dos filósofos acaece después del mayo del 68 y la subsecuente institución de la Université de Vincennes, Paris VIII. La leçon d'Althusser (1974) sería el primer libro del joven Rancière y funcionaría como carta abierta en contra de los dogmas del marxismo cientificista que predicaba su antiguo maestro. En este texto, Rancière pone de manifiesto las implicaciones de asumir que la masa ignora los mecanismos que la someten y es crítico ante la supuesta imposibilidad de una lucha emergida desde el contexto obrero. Para Rancière las presuposiciones teóricas althusserianas reprimieron el examen de la revuelta estudiantil del 68 y, en consecuencia, se refugiaron en la defensa de una -única- ciencia marxista que legitimaba la dominación. Bassas reconoce que Rancière, a diferencia de Althusser, asume la potencia de sublevación de n'importe qui -de cualquiera- sin escindir epistemológicamente entre los detentores de la verdad, por un lado, y la masa irreparablemente alienada, por el otro. En esta línea, Bassas hace referencia a La nuit des proletaires (1981), libro ejemplar sobre el modo ranciereano de escribir e investigar. Si bien este texto busca revisar la historiografía obrera, el método es inusual. Rancière compila las manifestaciones de la voz obrera a partir de la creación de un archivo conformado por cartas, poemas, diarios, confesiones y anotaciones. De este modo, señala cómo los obreros se apropian de su tiempo libre para escribir. Las voces obreras se emancipan, entonces, de la identidad que se les había asignado por su obligación de trabajar.

En el capítulo El desacuerdo: una igualdad sin fundamento, Bassas se propone pensar en la filosofía política de Rancière separada de la racionalidad política. Introduce la concepción de la comunidad ranciereana que aparece como el recuento de sus partes. Este implica una subjetivación política que asigna una voz o un lugar de visibilidad y es, en consecuencia una política estética. No obstante, en el recuento de las partes alguna sufre el agravio de no tener parte. La parte de los sin-parte son aquellos que no cuentan en el todo social (p. 72). Ante este agravio Bassas desentrama la política de los filósofos. Considera las lecturas que hace el propio Rancière de la República de Platón y la Política de Aristóteles. Hila, de este modo, un camino hacia la descripción de la archi-política como una política de correspondencia con el arkhé, la para-política como el telos del orden policial a partir de la justa distribución de lugares y la meta-política como la búsqueda de la verdad más allá de la sociedad a la que regula. Ahora, estas concepciones de la política preocupan por ser incompatibles con 
la praxis política de la igualdad. Por este motivo Bassas concluye que la política posfundacional de Rancière es una an-arquía -sin arkhé, sin principio-.

En el capítulo El escándalo de la democracia, Bassas retoma el libro La haine de la democratie (2005). Relata que éste responde a la una circunstancia sociopolítica precisa: los resultados del referéndum sobre la Constitución europea de mayo de 2005. La posición de los políticos confirmaba el odio a la democracia respaldado en que "el pueblo no sabe lo quiere y no ha sido capaz de entender la importancia de la Constitución europea" (p. 110). La democracia se pinta, en consecuencia, como un peligro para el buen gobierno o como "el reino de los deseos ilimitados de los individuos [consumistas] de la sociedad de masas moderna" (p. 114). Estas circunstancias se reproducen en el mundo por una crisis social en la que predomina la aspiración a los privilegios del individualismo por encima de la igualdad. A este respecto aparece la distinción de diferentes tipos de democracia: la democracia burguesa, la democracia rural y la democracia real. Rancière responde a estas nociones a partir de una noción radical: la democracia no puede ser una forma de gobierno sino un escándalo que (des)legitima y pone de manifiesto a un gobierno fundado en la nada. Bassas acentúa que lo excesivo de la democracia no es el deseo de consumo, sino la extensión ilimitada de la voz. En otras palabras, lo inconmensurable de la democracia yace en extender a cualquiera la capacidad para gobernar y para hablar de lo justo y lo injusto. Por lo tanto, lo excesivo es suponer la igualdad radical.

Bassas es preciso con el vocabulario ranciereano y lo utiliza en consideración de su propia argumentación. La atención que dedica Bassas a las nociones propuestas por Rancière permite argumentar acerca de los fundamentos políticos que imposibilitan la manifestación de la igualdad y apostar, en cambio, por una política posfundacional. Bassas ofrece este libro proponiéndose conversar sin negar la potencia de la voz de la lectora o el lector; asimismo, anticipa la voz que le hará preguntas y que intervendrá su texto. En este libro no hay pretensión de objetividad, sino de singularidad, porque sólo en esta medida es posible gesticular la igualdad.

Diana Mitzi González Fonseca 